\title{
Link Between Obesity and The Severity of COVID-19 Infection: A Multicenter Retrospective Study in Dubai
}

\author{
Mawada Hussein'), Amna Tahir'1), Iman Tabash'1), Mona Elhassan'), Nouha Azaza1), \\ Ahd Hassan'), Hamzeh Alsubbah'), Meeruna Narainen'), Laila AlDabal2) \\ 1)Internal Medicine Department, Rashid Hospital, Dubai Health Authority, United Arab Emirates \\ 2)Infectious Disease Department, Rashid Hospital, Dubai Health Authority, United Arab Emirates
}

\section{ABSTRACT}

Background: Obesity is a major contributing factor for poor prognosis in many diseases and COVID-19 is no exception. Studies regarding the relationship between obesity and poor COVID-19 disease severity and outcome are however lacking in the gulf region. This study aimed to examine links between BMI and high mortality rate, duration of intensive care unit admission, and time on mechanical ventilation support among COVID-19 patients under the care of Dubai Health Authority (DHA) in the United Arab Emirates.

Subjects dan Method: This was a retrospective, descriptive, record-based study of 637 patients admitted with confirmed SARS-CoV-2 PCR at three tertiary hospitals in Dubai, UAE. Demographic and clinical data were obtained from March 1st, 2020, through June 1st, 2020, all patients aged 18 and above were included, pregnant ladies were excluded. The dependent variables were ICU admission, COVID severity, need of respiratory support, viral clearance. The independent variables were the disease outcome between the obese and non-obese. The data were analyzed using chisquare test.

Results: Total 200 (31.4\%) were obese, while 435 (68.3\%) were not obese. Most patients (81\%) were male patients. Data Analysis reveals that obesity is associated with the risk of ICU admissions $(\mathrm{OR}=2.88,95 \% \mathrm{CI}=1.9$ to $4.37 ; \mathrm{p}<0.001)$. The findings also indicate that Covid-19 obese patients required higher respiratory support devices compared to non-obese patients $(35.8 \%$ vs $16.3 \%$, respectively) $(\mathrm{OR}=2.87,95 \% \mathrm{CI}=1.93$ to $4.27 ; \mathrm{p}<0.001)$. Clinical severity at day 7 th of hospital admissions among obese patients was direr compared to non-obese patients $(34.5 \%$ vs $15.9 \%$, respectively) $(\mathrm{OR}=2.79,95 \% \mathrm{CI}=1.87$ to $4.16 ; \mathrm{p}<0.001)$. Mortality rate at day 14 of admission were found higher among obese group too (9.5\% vs 3.4\%) $(\mathrm{OR}=2.95,95 \% \mathrm{CI}=1.46$ to $5.94 ; \mathrm{p}=0.020)$.

Conclusion: This study indicates that COVID-19 patients with obesity (BMI more than $30 \mathrm{~kg} / \mathrm{m}^{2}$ ) are found to have severer respiratory manifestations, higher mortality rate, prolonged periods of intensive care unit admission, and utilization of invasive mechanical ventilation.

Keywords: Obesity, COVID-19, respiratory support, disease outcome, ICU

\section{Correspondence:}

Mawada Hussein. Internal Medicine Department, Rashid Hospital, Dubai Health Authority, United Arab Emirates. Email: mamhussein@dha.gov.ae. Mobile: +971421910oo.

Cite this as:

Hussein M, Tahir A, Tabash I, Elhassan M, Azaza N, Hassan A, Alsubbah H, et al. (2021). Link Between Obesity and The Severity of COVID-19 Infection: A Multicenter Retrospective Study in Dubai. J Epidemiol Public Health. 06(03): 355-361. https://doi.org/10.26911/jepublichealth.2021.06.03.09.

(c) (7) (2) Journal of Epidemiology and Public Health is licensed under a Creative Commons Journal of Epidemiology and Public Health is licensed under a Creativ

\section{BACKGROUND}

In December 2019, a cluster of severe acute respiratory illnesses, now known as Coronavirus disease 2019 (COVID-19), occurred in Wuhan, Hubei Province, China. The disease has rapidly spread from Wuhan to other parts of the world, On March 11, 2020, coronavirus disease 2019 (COVID19) was declared a pandemic by the World Health Organization (WHO, 2020), the 
ministry of health and prevention in the United Arab Emirates (UAE) has announced the total confirmed Covid-19 cases have reached 532,710 with official death tolls 1,607 up to 8 May 2021 (National Emergency Crisis and Disaster Management Authority, 2021).

Research alternative therapeutic studies are focusing on ACE2 targeting. Existing evidence suggests that angiotensin-converting enzyme 2 (ACE2) is a SARS-CoV receptor (Kuba et al., 2005). ACE2 is found on the outer surface of cell membranes. Coronavirus attaches to the ACE2 and enters the cell to reproduce. ACE2 proteins have significant functions in our bodies. For example, ACE2 is a key element of the renin-angiotensin system (RAS). Which play a significant role in controlling blood pressure (Kuba et al., 2005). ACE2 is expressed in many tissues such as the intestine, kidney, blood vessels, and heart tissue. ACE 2 is largely found in the adipose tissue as well (Jia et al., 2020).

A growing body of scientific research in the literature links Covid's 19 severe symptoms with being overweight as adipose tissues act as a reservoir for SARS-CoV viral spread (Ekiz \& Pazarl,, 2020). It is known that obesity negatively impacts the wellbeing of the obese individual and elevates his/her risk of complications of many diseases. Center for Disease Control and Prevention (CDC), for example, lists obesity as a risk for influenza-related complications (Center for Disease Control and Prevention, 2021).

When the $\mathrm{H} 1 \mathrm{~N} 1$ Influenza $\mathrm{A}$ virus, commonly known as swine flu, caused significant numbers of deaths across the world (Louie et al., 2009), overweight has not been recognized as a major risk factor for influenza complications (Louie et al., 2009). However, during the California 2009 influenza $\mathrm{A}(\mathrm{H} 1 \mathrm{~N} 1)$ pandemic, a group of researchers examined patients with positive PCR of $\mathrm{A}(\mathrm{H} 1 \mathrm{~N} 1)$ who were reported to the California Department of Public Health (CDPH) between April 23 and August 11. More than half the cases reported to CDPH were obese and about $43 \%$ of adult patients were morbidly obese with BMI above 40 (Louie et al., 2009). These observations stressed the need of including obesity as an independent risk factor for influenza completion (Louie et al., 2009).

A similar pattern of association emerged between COVID-19 and obesity in China. A recent study examined the data of COVID-19 patients admitted to Shenzhen Covid referral hospital for a period of one month. They found that obese individuals face a higher health risk for developing severe COVID-19 than non-obese individuals $(\mathrm{OR}=3.40 ; 95 \% \mathrm{CI}=1.40$ to2.86; $\mathrm{p}=$ 0.007) (Cai et al., 2020)

In Europe, where the prevalence of obesity is higher than in China, a team of physicians at Roger Salengro Hospital, in France, studied SARS-CoV-2 patients who were admitted to intensive care units (ICU). Obesity among ICU patients was dominant about $75.8 \%$ out of 124 patients (Simonnet et al., 2020). The need for invasive mechanical ventilation (IMV) was significantly high among obese compared to non-obese (Simonnet et al., 2020). In the Arabian Peninsula, there is not enough research that focuses on COVID-19 infection among obese patients in the region. Therefore, one of the main objectives of this study is to examine the associations between BMI and coronavirus disease 2019 under the care of DHA in UAE. The second objective is to compare whether our finding matches or opposes current COVID-19 research findings in the literature. 


\section{SUBJECTS AND METHOD}

1. Study Design:

This is a retrospective multicentered study done from three major hospitals under the care of DHA; Rashid, Latifa, and Dubai hospitals, UAE that involves 637 adult patients (non-pregnant) aged 18 and above with confirmed SARS-CoV-2 PCR from March 1st, 2020, through June 1st, 2020.

\section{Population and sample:}

The stochastic method was used to extract data from patients' Electronic Medical Records (EMR). The first hospital is Rashid Hospital, which is considered a major disaster facility that covers the Northern Emirates. Rashid Hospital has been a JCI accredited hospital since October 2007 (Dubai Health Authority, 2021). Latifa Women and Children Hospital with a bed capacity of 344 (Dubai Health Authority, 2021). Latifa Hospital is recognized with high quality of patient care and its sophisticated medical equipment. The third center is Dubai Hospital. Dubai Hospital is a multispecialty medical center with 600-bed capacities (Dubai Health Authority, 2021).

\section{Study Instrument}

A predesigned excel sheet was developed that includes baseline demographics, BMI, medical history, vitals, imaging, labs, patient's clinical severity, intensive care requirement from Electronic Medical Records of patients.

\section{Study Variables}

The dependent variables were ICU admission, COVID severity, need of respiratory support, viral clearance. The independent variables were the disease outcome between the obese and non-obese.

\section{Definition Operational of Study}

Clinical severity score; based on chest Xray, vitals, and oxygen saturation on day 7 of admission and categorized into mild, moderate, and severe disease.
Respiratory support; based on which oxygen supplementation device is used during admission into the following: room air, nasal canula, non-rebreathe able mask, high flow nasal cannula, non-invasive ventilator, mechanical ventilation.

Viral clearance; measured as the date of the first true negative PCR result. For the purpose of this study, 21 days were chosen as a reference.

\section{Data analysis}

SPSS 24 was used for statistical analysis (IBM Corp. Released 2016. IBM SPSS Statistics for Windows, Version 24.0. Armonk, NY: IBM Corp). Categorical data are presented as count and percent. A chi-square test was used to compare ICU admission, COVID severity, the need for respiratory support, viral clearance, and the disease outcome between the obese and non-obese. Odds ratios with $95 \%$ confidence interval, also, was reported. $\mathrm{P}<0.05$ indicate statistical significance.

\section{Research Ethics}

The research was done solely through retrospective observation and data collection which by no means contradicted the health being of the selected patients.

\section{RESULTS}

A total number of 637 patients who were treated under the care of Dubai Health Authority hospitals (Rashid, Dubai, Latifa) from $1^{\text {st }}$ March 2020 till $1^{\text {st }}$ June 2020 were included in this study (aged 18 years and older, non-pregnant).patient who did not fulfill the inclusion criteria were excluded.

As shown below (table 1), the average age of the studied patients was relatively young and most of them were male $81 \%$, with a mean age of 42 years, out of the total number of patients 435 (68.3\%) were not obese, while $200(31.4 \%)$ were obese with $\mathrm{BMI}>30 \mathrm{~kg} / \mathrm{m}^{2}$. 
Husein et al./ Obesity and The Severity of COVID-19 Infection

Table 1. Patients Chartactrestics

\begin{tabular}{llcc}
\hline \multicolumn{1}{c}{ Characteristics } & \multicolumn{1}{c}{ Category } & Frequency & Percentage \\
\hline Age & <40 years old & 299 & 46.9 \\
& 40-60 years old & 286 & 44.9 \\
\multirow{3}{*}{ Gender } & > 60 years old & 52 & 8.2 \\
& Female & 123 & 19.3 \\
BMI (Body Mass Index) & Male & 514 & 80.7 \\
& Obese & 200 & 31.4 \\
& Non obese & 437 & 68.8 \\
\hline
\end{tabular}

As shown in table 2, respiratory support with different devices at day seven of admission was statistically analyzed; among the studied population, 68 obese patients (35.8\%) required high respiratory support devices (in terms of HFNC, NRM, NIV, $\mathrm{MV})$, compared to 66 non-obese patients (16.3\%), it was found that obesity increase the odds of requiring high respiratory needs $(\mathrm{OR}=2.8795 \% \mathrm{CI}=1.93$ to $4.27 ; \mathrm{p}<0.001)$.

Clinical severity at 7 days of admission was analyzed; 67 obese patients were labeled as clinically severe/critical/ deceased (34.5\%), compared to 64 nonobese patients $(15.9 \%)(\mathrm{OR}=2.79 ; 95 \% \mathrm{CI}=$ 1.87 to 4.163 ; $\mathrm{p}<0.001)$.

Table 2. Clinical Characteristics in Obese and Non-Obese Groups

\begin{tabular}{|c|c|c|c|c|c|c|}
\hline \multirow{3}{*}{ Variables } & \multicolumn{4}{|c|}{ BMI } & \multirow{3}{*}{$\mathbf{O R}$} & \multirow{3}{*}{$\mathbf{p}$} \\
\hline & \multicolumn{2}{|c|}{ Obese } & \multicolumn{2}{|c|}{ Non-Obese } & & \\
\hline & $\mathbf{N}$ & $\%$ & $\mathbf{N}$ & $\%$ & & \\
\hline ICU Admission & 58 & 29 & 54 & 12.4 & 2.88 & $<0.001$ \\
\hline Disease Severity at day 7 (severe/critical) & 67 & 34.5 & 64 & 15.9 & 2.79 & $<0.001$ \\
\hline High Respiratory support & 68 & 35.8 & 66 & 16.3 & 2.87 & $<0.001$ \\
\hline Outcome at day 14 (mortality) & 19 & 9.5 & 15 & 3.4 & 2.95 & 0.020 \\
\hline
\end{tabular}

COVID-1 9 viral clearance through PCR was analyzed among the studied population; 45 obese patients (27.1\%) cleared the virus after 21 days compared to 84 non-obese patients $(21.4 \%)$ with no statistical significance between the two categories, $\mathrm{p}=1.460$.

\section{DISCUSSION}

We aimed to study the effect of obesity on COVID19 disease severity at presentation and on day 7 of admission in terms of requiring additional respiratory support
58 obese patients required ICU admission during the study period (29\%), compared to 54 non-obese patients (12.4\%) between the two groups. Obesity increases the odds of being admitted to ICU (OR= 2.88; $95 \% \mathrm{CI}=1.9$ to $4.37 ; \mathrm{p}<0.001$ ).

Patients' outcome on day 14 of admissions was assessed, for statistical purpose patients were categorized either as deceased or not at day 14 and analyzed, it was found that 19 obese patients were deceased (9.5\%), compared to 15 non-obese (3.4\%), obesity increase the odds at day 14 of being deceased with (OR $=2.95,95 \% \mathrm{CI}$ 1.46 to $5.94 ; p=0.020$ ). (noninvasive ventilator, high flow oxygen delivery devices, invasive mechanical ventilation), clinical severity at day 7 of admission, viral clearance at day 21 of admission and clinical outcomes (deceased, discharged/ transferred, worsened, inpatient) measured at 14 days of admission admitted as SARS-CoV-2 under Dubai Health Authority (which includes Rashid, Latifa and Dubai Hospitals).

Obesity increases the odds of being admitted to ICU. The strong association 
between ICU requirement's and Obese COVID-19 patients as illustrated in multiple various studies for example in one study total of 265 patients admitted to ICU at university hospitals at Johns Hopkins, University of Cincinnati, New York University, University of Washington, Florida Health, and University of Pennsylvania the correlation between BMI and age in patients with COVID-19 were examined, it was found that there is a significant inverse correlation between age and BMI, The median BMI was $29 \cdot 3 \mathrm{~kg} / \mathrm{m}^{2}$, with only $25 \%$ of individuals having a BMI of less than 26 $\mathrm{kg} / \mathrm{m}^{2}$, and $25 \%$ exceeding a BMI of $34 \cdot 7$ $\mathrm{kg} / \mathrm{m}^{2}$. Thus, concluded in populations with a high prevalence of obesity the younger population might be affected with the severe disease more than it was previously reported (David et al., 2020).

As well in France, a study was done between February 27, 2020, and April 5, 2020, a total of 124 patients were admitted in intensive care for SARS-CoV-2, it was found that the risk of the invasive mechanical ventilator was higher for those with obesity reaching nearly $90 \%$ in patients with $\mathrm{BMI} \geq 35$ (Simonnet et al., 2020).

In our studies, it was found that obesity increase the odds of severe COVID19 disease at day 7 of admission. A similar study designated hospital in Shenzhen china a total of 383 hospitalized patients with COVID-19 admitted from 11 January 2020 to 16 February 2020 and followed until 26 March 2020, it was found that those who were obese (obesity as $\mathrm{BMI} \geq 28$ $\mathrm{kg} / \mathrm{m}^{2}$ ) were at 3 times fold at risk of developing the severe disease (Cai et al., 2020).

Unlike the hypothesis formulated at the start of this study, there is no significant statistical significance between viral clearance in obese and non-obese patients. This study concluded that obesity (BMI >30 $\mathrm{kg} / \mathrm{m}^{2}$ ) significantly increases the risk of poor COVID-19 disease outcome, disease clinical severity, intensive care requirements compared to non-obese patients.

This is a retrospective observationalbased study; further studies are needed to investigate and follow up on the clinical outcome of COVID-19 obese patients. Several complications of COVID-19 disease in those sample populations were not studied. There is no long-term follow-up beyond the study time frame for the studied patients. While our finding needed further prospective study, this study is a pioneer study in the Arabian Gulf countries and might be used as an initial study to generate stronger evidence-based studies.

\section{CONFLICT OF INTEREST}

The authors report no relationships that could be construed as a conflict of interest.

\section{FUNDING AND SPONSORSHIP}

No financial contribution, sponsorship, or grants have been received for this study.

\section{AUTHORS CONTRIBUTION}

All participant investigators in this study were enrolled in data acquisition, data interpretation, and data analysis processes. In addition to that, they provided their constructive critique throughout the study duration. A consensus was given from all participating investigators and supervisors for the authenticity and integrity of the carried work.

\section{ACKNOWLEDGMENT}

I would like to express my very great appreciation to Dr. Laila AlDabal for her valuable and constructive suggestions during the planning and development of this research work. Her willingness to give her time so generously has been very much appreciated. I would also like to thank all 
the participating investigators for devoting their time and efforts to contributing to the fruition of this research work.

\section{REFERENCE}

Cai Q, Chen F, Wang T, Luo F, Liu X, Wu Q, He Q, et al. (2020). Obesity and COVID-19 Severity in a Designated Hospital in Shenzhen, China. Diabetes Care. 43(7): 1392-1398. doi: 10.2337/dc20-0576.

CDC (2018). People at High Risk for Flu Complications. Centers for Disease Control and Prevention. Retrieved from https://www.cdc.gov/flu/highrisk/index.htm.

Dehingia N, Raj A (2020). Sex differences in COVID-19 case fatality: do we know enough? The Lancet Glob Health. 9(1):e14-e15. doi: 10.1016/S2214-109$\mathrm{X}(20) 30464-2$.

DHA-Dubai Health Authority. Dha.gov.ae. Retrieved from https://www.dha.gov. ae/en/Pages/DHAHome.aspx\#.

Ekiz T, Pazarlı AC (2020). Relationship between COVID-19 and obesity. Diabetes Metab Syndr. 14(5): 761-763. doi: 10.1016/j.dsx.2020.05.047.

Jia X, Yin C, Lu S, Chen Y, Liu Q, Bai J, Lu $Y$ (2020). Two Things about COVID19 Might Need Attention. Preprints. doi:

10.20944/preprints202002.0315.v1.

Kass DA, Duggal P, Cingolani O (2020). Obesity could shift severe COVID-19 disease to younger ages. Lancet. 395(10236): 1544-1545. doi: 10.1016/So140-6736(20)31024-2.

Kuba K, Imai Y, Rao S, Gao H, Guo F, Guan B, Huan Y, et al. (2005). A crucial role of angiotensin-converting enzyme 2 (ACE2) in SARS coronavirus-induced lung injury. Nat. Med. 11(8): 875-879. doi:10.1038/nm1267.

Louie JK, Acosta M, Winter K, Jean C,
Gavali S, Schechter R, Vugia D, et al. (2009). Factors associated with death or hospitalization due to pandemic 2009 influenza $\mathrm{A}(\mathrm{H} 1 \mathrm{~N} 1)$ infection in California. JAMA. 302(17): 18961902. doi: 10.1001/jama.2009.1583.

Simonnet A, Chetboun M, Poissy J, Raverdy V, Noulette J, Duhamel A, Labreuche J, et al. (2020). High prevalence of obesity in severe acute respiratory syndrome coronavirus-2 (SARS-CoV2) requiring invasive mechanical ventilation. Obesity (Silver Spring). 28(7): 1195-1199. doi: 10.1002/oby.22831.

Tartof SY, Qian L, Hong V, Wei R, Nadjafi RF, Fischer H, Li Z, et al. (2020). Obesity and Mortality Among Patients Diagnosed With COVID-19: Results from an Integrated Health Care Organization. Ann Intern Med. doi: 10.7326/M20-3742.

UAE (2020). Coronavirus (COVID-19). Retrieved from https://covid19.ncema.gov.ae/en.

WHO (2020). Coronavirus Disease (COVID-19) - Events as They Happen. Retrieved from https://www.who.int/ emergencies/diseases/novel-coronavirus-2019/events-as-they-happen.

World Bank Open Data|Data, n.d. Retrieved from https://data.worldbank.org/.

WHO (2020). Coronavirus Disease (COVID -19) Situation Reports.

World Population Growth - Our World in Data, n.d. Retrieved from https://ourworldindata.org/world-populationgrowth.

You H, Wu X, Guo X (2020). Distribution of covid-19 morbidity rate in association with social and economic factors in wuhan, china: Implications for urban development. Int. J. Environ. Res. Public Health 17 (10): 3417. 
Husein et al./ Obesity and The Severity of COVID-19 Infection

doi: 10.3390/ijerph17103417.

Zhou F, Yu T, Du R, Fan G, Liu Y, Liu Z, Xiang J, et al. (2020). Clinical course and risk factors for mortality of adult inpatients with COVID-19 in Wuhan, China: a retrospective cohort study. Lancet 395(10229):1054-1062. doi: 10.1016/So140-6736(20)30566-3. 